\title{
Diet, Nutrients and Noncommunicable Diseases
}

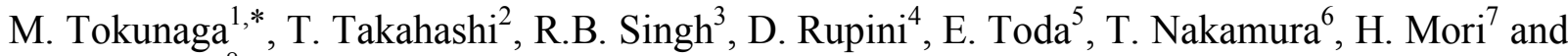 \\ D.W. Wilson ${ }^{8}$
}

${ }^{I}$ Department of Nutrition and Health Sciences, Fukuoka Women's University, Fukuoka, Japan

${ }^{2}$ Graduate School of Human Environment Science, Fukuoka Women's University, Japan

${ }^{3}$ Halberg Hospital and Research Institute, Moradabad, India

${ }^{4}$ Food Science \& Nutrition, University of Mysore, Manasagangothri, Mysore, India

${ }^{5}$ Tokai University Hachioji Hospital, Tokyo, Japan

${ }^{6}$ The Japan Dietetic Association, Tokyo, Japan

${ }^{7}$ Aomori Prefecture Hospital, Aomori City, Japan

${ }^{8}$ School of Medicine and Health, Durham, UK

\begin{abstract}
There is a marked increase in our knowledge about the role of the nutritional factors in the global dimensions of the noncommunicable diseases (NCDs). Recent studies indicate that there is coexistence of nutritional deficiencies and appreciable over-nutrition in conjunction with physical inactivity, due to urbanization and industrialization. Dietary factors may predispose inflammatory dysfunctions in tissues predisposing to central obesity and overweight that are risk factors of NCDs. Mortality and burden of disease estimates for WHO Member States in 2008, clearly showed that the gratifying gains in cardiovascular health occurred in developed countries, in association with an epidemic of CVD in the developing world. Singh et al., proposed, modifying the previous hypothesis, that overweight comes first in conjunction with inflammation, hyperinsulinemia, increased angiotensin activity, vascular variability disorders and central obesity followed by glucose intolerance, type 2 diabetes, and hypertension. This sequence is followed by coronary artery disease (CAD), gallstones and cancers and finally dental caries, gastrointestinal diseases, bone and joint diseases, degenerative diseases of the brain and psychological disorders, during transition from poverty to affluence. It seems that all the NCDs are mediated by inflammation due to interaction of biological systems with dietary factors, including deficiency of nutrient rich functional foods and excess of rapidly absorbed energy-rich foods. Epidemiological studies indicate that as people become rich, they begin to increase their intake of pro-inflammatory refined foods; dietary w- 6 and trans fat, salt and sugar in the form of ready prepared refined foods, syrups, dairy products and fresh foods in place of grain and vegetable-based diet which have been found protective against NCDs. There is an increase in sedentary behavior due to adoption of sedentary occupations, which also enhances the inflammation, dyslipidemia and obesity. A Mediterraneanstyle diet rich in nutrients, moderate physical activity and moderation in alcohol intake appear to be protective against NCDs.
\end{abstract}

Keywords: Diet, lifestyle, inflammation, chronic diseases, cardiovascular diseases.

\section{INTRODUCTION}

The world has been in a position to learn the role of nutritional factors and other risk factors, during transition from poverty to economic development and emergence of NCDs [1-8]. A well-balanced diet is a cornerstone of good health and therefore a wide ranging plan is recommended by the International College of Nutrition, International College of Cardiology and WHO for food and nutrition policy to tackle noncommunicable diseases (NCDs) [1-4]. In this

*Address correspondence to this author at the Department of Nutrition and Health Sciences, Fukuoka Women's University, Fukuoka, Japan;

Tel: 0091 5912417437; E-mail tokunaga@fwu.ac.jp plan the key point is comprehensive and understandable information on health nutrition, engaging health care providers to influence individuals' diet and lifestyle choices, and instituting surveillance systems for nutritional status, food consumption, tobacco intake and physical activity patterns [5-8]. A recent study from India by the Five City Study Group, sponsored by the International College of Nutrition has also described the Triple Burden of Diseases including undernutrition, overnutrition and sedentary behavior as principal risk factors of NCDs [2]. The United Nations and other world leaders have placed emphasis on the global importance of the NCDs including mental diseases [9-31]. This shift toward increased obesity and NCDs is only the latest pattern of this transition $[2,31,32]$. The other 
patterns of the nutrition transition are given below. The first pattern, which is linked with hunter-gather societies and is often called the Paleolithic pattern was one in which the diet was very healthy, but infectious diseases and other natural causes resulted in a very short life span [23-25]. The second pattern, when modern agriculture and a period of famine emerged, was one in which nutritional status worsened. Most attention is focused on nutrition shifts in the last 3 patterns, which are generally the ones represented by most of the global population today [1-4]. In pattern 3, famine begins to recede as income rises. In pattern 4 , changes in diet and activity patterns lead to the emergence of new diseases and increases disability. In pattern 5 , behavioral change begins to reverse the negative tendencies of the preceding patterns and enable a process of successful aging [3-5]. A range of factors; including urbanization, economic growth, technical change, and culture drives all the changes during these stages of transition. Western diet is characterized by energy dense, refined, ready prepared foods with a high glycemic index (e.g., refined starches; bread, biscuits, candies, cornflakes, pizza, potato chips, cola drinks and sugar) and unhealthy lipids (e.g., trans fats, saturated fat, w-6 rich oils) poor in phytochemicals and fiber [1-4]. Such diets have been adopted by increased numbers of people and populations in the Western world and in the urban populations of middleincome countries in the last few decades [1-4]. These diets are known to predispose the epidemic of NCDs. Cardiovascular disease (CVD) and other chronic diseases such as cancer, autoimmune diseases, diabetes and asthma are associated with greater levels of prostacyclins, leukotrienes, and thromboxanes [23-25].

Greater consumption of energy rich foods containing high trans fat, saturated fat and w-6 fat and refined carbohydrates in conjunction with physical inactivity are known to enhance all these biomarkers which have adverse proinflammatory effects resulting into NCDs [1-12]. These foods are also known to cause dyslipidemia leading to metabolic syndrome [1-4]. Recent studies indicate that a Mediterranean diet rich in fruits, vegetables, nuts, canola oil, olive oil as well as physical activity, and meditation can decrease inflammation and may be protective against risk of CVD and all-cause mortality [1-6]. Inflammation appears to be an important unifying hypothesis in the pathogenesis of NCDs because the entire primary risk factors; diet, physical inactivity, tobacco, mental load, and alcoholism are known to cause inflammation [1-8]. A schema for the emergence of chronic diseases with respect to the interaction of genes and the environment is shown in Fig. (1) [19] where changing dietary intake arising from the transition from poverty to affluence gives rise to successive gradations of NCDs.

\section{NONCOMMUNICABLE DISEASES}

The last decade of the last century offered us an opportunity to initiate action to counter growing epidemics of cardiovascular diseases (CVD) on both sides of the Atlantic [9-18]. There was a declining trend in CVD in the Western world after 1968, but obesity continued to increase, resulting in an increase in the metabolic syndrome in both developed and developing economies leading to increased burden and mortality due to NCDs $[12,15,16]$. Therefore, in September 2000, the United Nations made a Millennium declaration and set 8 Millennium development goals to focus international development efforts on decreasing global poverty by 2015 [9]. Of the 8 Millennium development goals, 3 goals directly address health of the people and populations, without mention of NCDs, health and general education but for human development. The United Nations High-Level Meeting (UN HLM) on deaths and disability due to NCDs held in September, 2011 has been very exciting [9-13]. The world's Heads of States and Health Ministers attended the meeting, creating a unique opportunity to advance globally the prevention and treatment of NCDs. The burden of death and disability attributable to NCDs is rising in all middle- and high-income countries, because of the rapid changes in the lifestyle patterns [12]. Millions of deaths occur every year due to lack of health education and poor health policies. NCDs are a great challenge to health care experts and governments and appear to be an underlying cause for poverty as well as threat to human, social, and economic development. The $36 \cdot 1$ million deaths per year as a result of NCDs represent almost two out of three deaths per year worldwide. 22.4 million of these deaths arise in the poorest countries, and 13.7 million in high-income and upper-middle-income countries [12]. Approximately, twothirds $(63 \%)$ of premature deaths in adults (aged 15-69 years), and three of four of all adult deaths are attributable to NCDs. NCDs emerge in a sequence during transition from poverty to affluence and ageing of the populations. Some of the NCDs such as coronary artery disease (CAD) and chronic respiratory diseases related to tobacco consumption are more common among lower-income and lower-middleincome countries, despite modest increase in overweight and obesity [7-9]. In 1970s, NCDs were less common among lower-income populations with life expectancy below 60 years, because of the enormous occupational physical activity and unavailability of automobiles and televisions

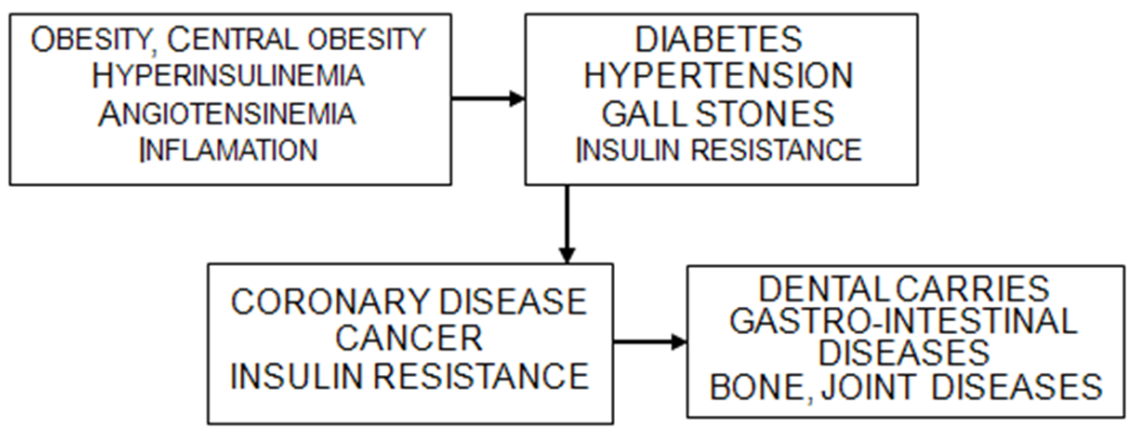

Fig. (1). Emergence of chronic diseases due to interactions of gene and environment (Singh et al., 1999, modified from Burkitt and Trowell). 
[15-20]. However, now there are as many deaths in women as there are in men, and poor people are disproportionately affected due to a decrease in occupational physical activity and easy availability of automobiles and televisions. WHO has emphasized that NCD death rates are already much higher in low-income and lower-middle- income than in high-income countries which may be due to lack of health education among these populations (Fig. 2). In almost all the countries of the world, NCDs are the major health issue for men and women, and are a serious issue for all health-care systems. NCDs also account for half of all global disability. In lower-income and lower-middle-income countries, where the majority of the population has no access to public health care and health insurance, the consequences of NCDs are tremendous. If a family member suffers from diabetes, cancer, or heart disease in these countries, these diseases often lead to a slow and painful death. It is surprising that the UN HLM (High-Level Meeting has focussed on just the four main NCDs and their shared risk factors. The UN member states realized that the agenda was already very broad and complicated but there was a need to start with a few diseases that will lead to systems of health care to address all NCDs. It is known that mental health issues such as depression, anxiety and hyperactivity disorders and NCDs are interrelated, hence treatment and prevention of NCDs would also have positive beneficial effects on mental health $[21,22]$. As a matter of fact, UN HLM should have considered only cardiovascular diseases (CVDs) and type 2 diabetes mellitus which are otherwise taking away all the resources, funds and brains for palliative care of these problems.

\section{RISK FACTORS OF NONCOMMUNICABLE DISEASES}

The world population has been under transition from Homo sapiens to homo economicus communities after the ancient agricultural revolution, some 10,000 years ago, when humans started farming and storing of foods. They continued to eat Paleolithic foods along with whole grains obtained from their farming and animal foods by hunting associated with enormous physical activity [23-25]. The major changes in the risk factors for NCDs have mainly occurred in the last 100 years after 1910 due to industrialization and urbanization resulting in rapid changes in the diet and lifestyle with emergence of risk factors of NCDs first in the developed countries and then in all other countries [26-34]. The major primary risk factors for CVDs and type 2 diabetes mellitus are identical to those of other NCDs including cancer and chronic respiratory diseases where pollutants, tobacco, allergens and carcinogens are more important [7, 8, 32-34]. In most developed countries, the emphasis is on primary risk factors such as nutrition, tobacco, alcoholism and physical activity is minimal and role of diet and nutrients are not given due consideration due to growing interest of the homo economicus community in the capitalist culture, where the sole aim is to enhance profit [34-36]. Unfortunately the whole world is following the culture and systems prevalent in these countries, whether it is housing, consumer durables; automobiles, indoor recreations, fashion, late night awakening, eating and drinking and empowering with weapons with little consideration for no tobacco, moderate alcohol, regular physical activity, meditation which are rapidly adopted in high-income countries. Majority of the risk factors and health problems benefit from continuity of care; strengthening primary health-care services to deliver longterm care for all disabling illnesses will benefit patients with mental health issues and people with other NCDs e.g., kidney disease and musculoskeletal disorders [10, 21, 22]. Health education about pathogenesis of various risk factors early in life emphasizes the importance of prevention of NCDs during the lifetime of an individual. It is important to educate girls and women before conception about their health and nutrition to achieve better health during pregnancy [26-31]. In respect of such healthcare services, Fig. (2) demontrates the potential for the 'rise and fall of Homo economicus' with increasing capital generation and man's changing behavioural patterns in a growing urban civilization and environment leading to the increasing development and expression of risk factors and ensuing global consequences of 'epidemic' proportions of morbidity and mortality of NCDs: though Communicable Diseases are also pressing problems, globally. Tobacco use, including exposure to second-hand smoke, diets high in refined carbohydrates, saturated fat, w- 6 fat and trans fat, salt, and sugar, low in w-3 and monounsaturated fatty acids (MUFA) and antioxidants and environments that prevent physical activity, and increased alcoholism and mental stress are

\begin{tabular}{|c|c|c|}
\hline Environmental Risk Factors & \multicolumn{2}{|c|}{ Behavioural } \\
\hline $\begin{array}{l}\text { Urbanization } \\
\text { Globalization } \\
\text { Low health education } \\
\text { Mental load }\end{array}$ & \multicolumn{2}{|c|}{$\begin{array}{l}\text { Tobacco } \\
\text { Unhealthy diet } \\
\text { Physical inactivity } \\
\text { Circadian disruption }\end{array}$} \\
\hline \multicolumn{2}{|c|}{ Biological Risk Factors } & Noncommunicable Diseases \\
\hline \multicolumn{2}{|c|}{$\begin{array}{l}\text { High blood glucose } \\
\text { Abnormal blood lipids } \\
\text { High C-Reactive protein } \\
\text { High plasma insulin } \\
\text { Abnormal Waist/hip ratio } \\
\text { High blood pressure } \\
\text { Abnormal lung function }\end{array}$} & $\begin{array}{l}\text { Heart disease } \\
\text { Stroke } \\
\text { Cancer } \\
\text { Chronic lung disease } \\
\text { Type } 2 \text { diabetes } \\
\text { Degen brain diseases }\end{array}$ \\
\hline
\end{tabular}

Fig. (2). Pathway for development of noncommunicable disease. 
important behavioural risk factors $[1-8,23,25,31]$. These risk factors are results of industrialization, urbanization and globalization which increase biological risk factors; obesity, increased blood pressure and concentrations of glucose and lipids and proinflammatory cytokines which are now common in the poorest countries, and are rising rapidly [32-34]. Underlying these biological risk factors are socioeconomic determinants such as poverty, inequality, unemployment, social instability, unfair trade, and global imbalances, which appear to be the root causes of the pandemic of NCDs [34-39] (Fig. 2).

\section{BURDEN OF NONCOMMUNICABLE DISEASES}

The total world population in 2011 was above 7.0 billion which may probably increase to 7.9 billion by the year 2025 . Adult population aged 20-79 years, in the world was 4.1 billion, in the year 2007, which would increase to 5.2 billion by the year 2025 . Of the total world's population, $80 \%$ of them live in developing countries and $80 \%$ of all CVD deaths occur in lower- and upper-middle income countries [39-41] (Figs. 3, 4). As mentioned earlier, 36.1 million deaths per year as a result of NCDs represent almost two of three deaths per year worldwide. Of these deaths, 22.4 million arise in the poorest countries, and 13.7 million in highincome and upper-middle-income countries [11, 12]. Fig. (3) shows mortality data (millions) from the World Bank for income groups illustrating three main points: a) that mortality from NCDs relative to injury and communicable diseases increase from poverty to affluence; b) by far the largest group for NCD mortality is in the lower-middle income group; and c) it is b) who experience a higher mortality due to injury and communicable disease which are very important but outside the scope of this report. However, when agestandardized mortality data is expressed for the same income groups by selected countries (Fig. 3), it is clear that a similar order from poverty to affluence prevails though other factors are important such as health care services provision, quality of housing, urbanization, crops and animal husbandry, education, etc., will all have an impact on mortality quite apart from communicable diseases. NCDs, principally CVD, cancer, chronic respiratory disease and diabetes mellitus caused 35 million deaths, which were $60 \%$ of total deaths in the year 2005. CVDs are the leading chronic diseases, with 17 million deaths. Deaths due to diabetes are usually recorded as being deaths due to heart disease, stroke and renal failure $[10,12,17,18]$. Majority of these deaths $(80 \%)$ occurred in low- and middle-income countries. In one recent study $[15,16]$, all-causes mortality were; infectious diseases $(41.1 \%, \mathrm{n}=915)$ such as tuberculosis, pneumonia, chronic obstructive pulmonary disease, diarrhea,/dysentery, hepatitis $\mathrm{B}$, inflammatory brain infections are the commonest cause of deaths in the urban population of north India. The second most common causes of deaths were circulatory diseases $(29.1 \%, \mathrm{n}=646)$ including heart attacks $(10.0 \%)$, stroke (7.8\%), valvular heart disease $(7.2 \%, \mathrm{n}=160)$, sudden cardiac death and inflammatory cardiac disease, each $(2.0 \%, \mathrm{n}=44)$. Malignant neoplasm $(5.8 \%, \mathrm{n}=131)$, injury $(14.0 \%, \mathrm{n}=313)$ including accidents, fire and falls and poisonings, were also quite common causes of death. Miscellaneous causes of deaths were noted in $9.1 \%,(\mathrm{n}=202)$ death records, including diabetes mellitus $(2.2 \%, \mathrm{n}=49)$, suicides $(1.8 \%, \mathrm{n}=41)$, congenital anomalies $(1.0 \%, \mathrm{n}=37)$, dental caries infections $(1.9 \%, \mathrm{n}=42)$, and burns $(1.3 \%, \mathrm{n}=33)$. Pregnancy and perinatal causes $(0.72 \%, \mathrm{n}=15)$ were not commonly recorded in this study. NCDs as the cause of death were common among $68 \%$ of the victims dying due to various causes. According to the Registrar General of India, in the year 1994 to 1998 , trends indicate that there has been a significant decline of proportionate deaths from infectious diseases from $22 \%$ to $16 \%$. However, mortality from cardiovascular disease (CVD) increased from $21 \%$ to $25 \%$ which is lower than the

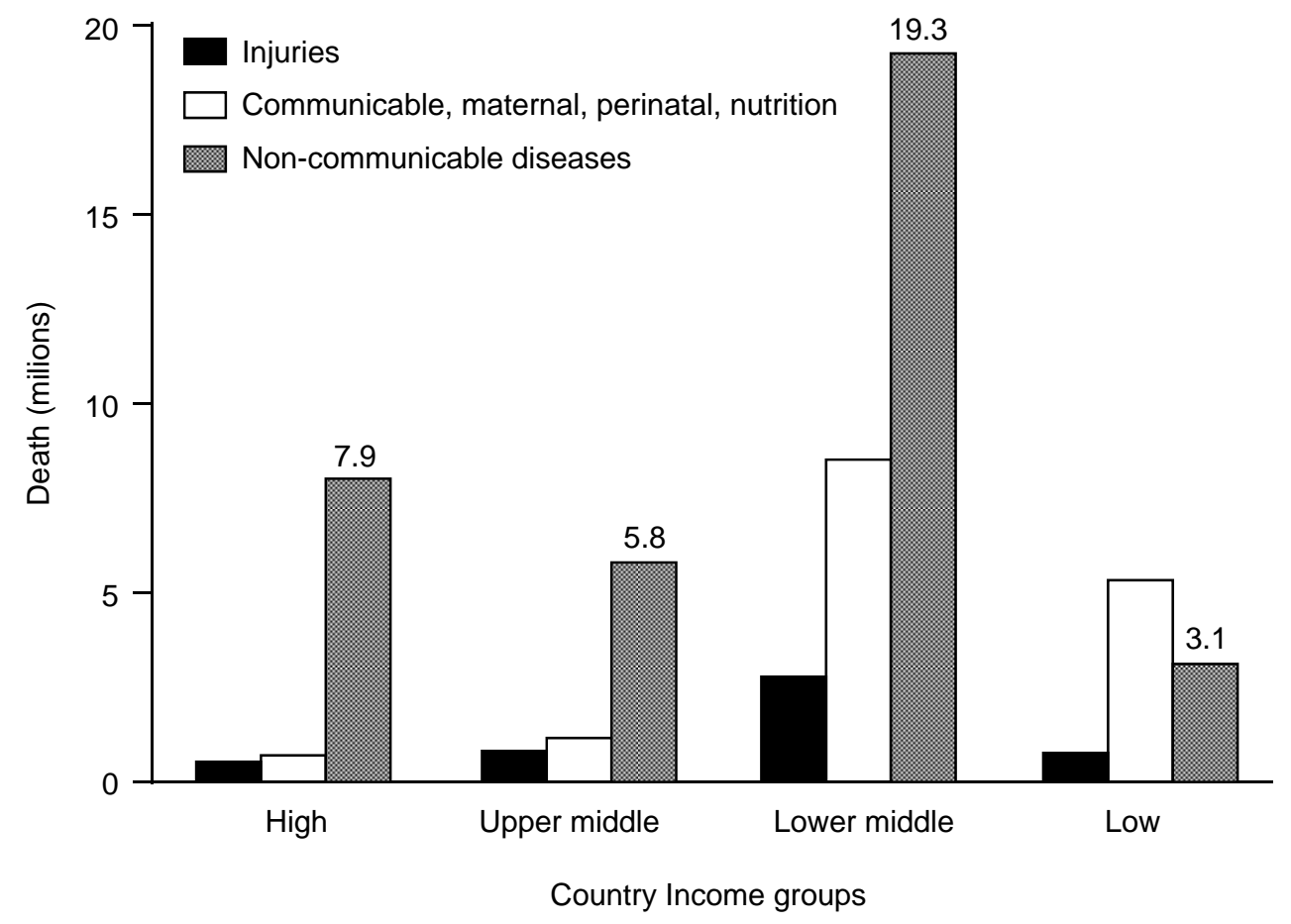

Fig. (3). Broad cause of death in countries, by World Bank income groups, 2008. 


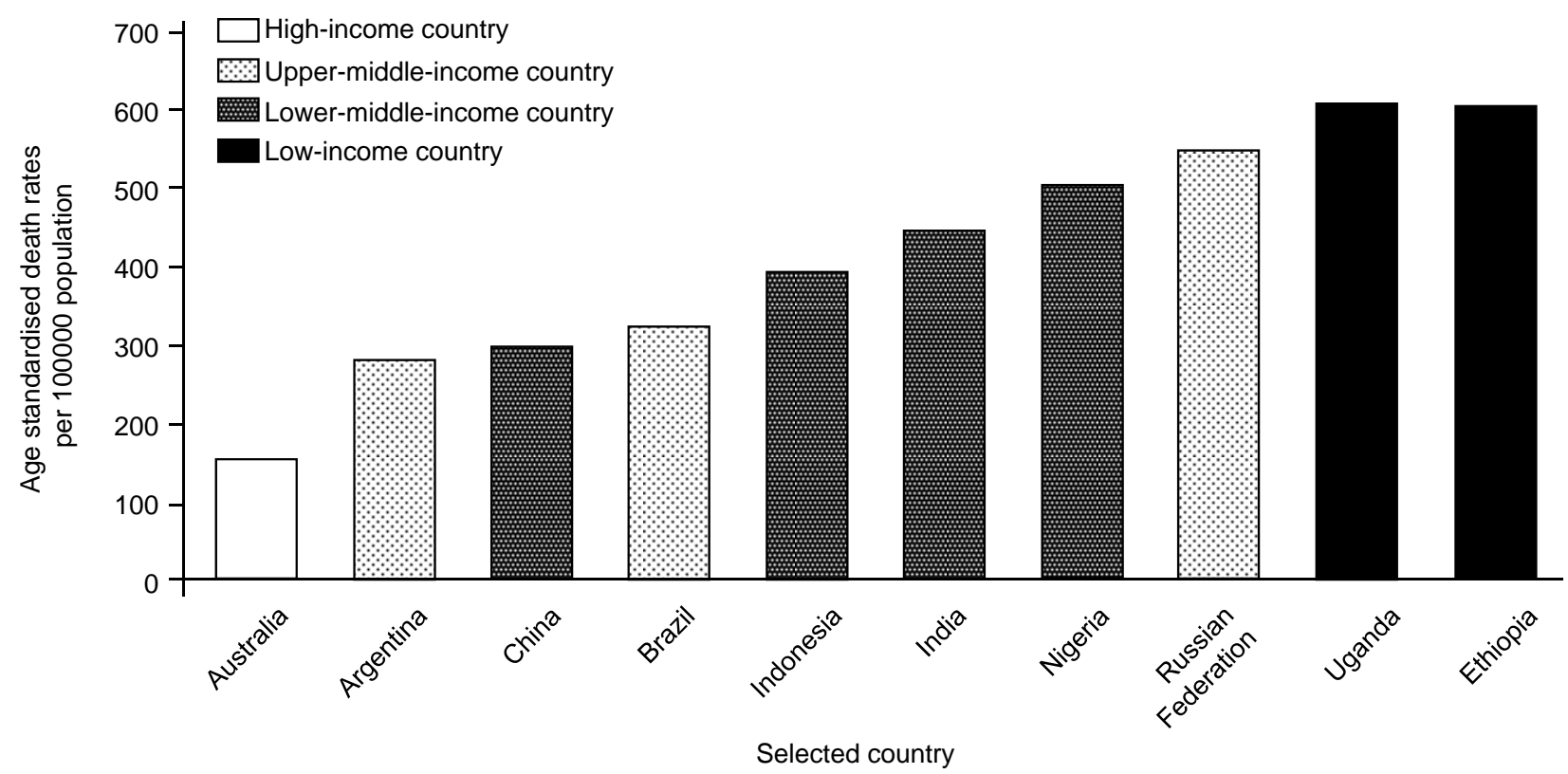

Fig. (4). NCD death rates in people aged 15-69 years, by World Bank income groups, 2008. NCD=non-communicable diseases.

death rate of 29.1 reported by Singh et al., in $2005(15,16)$. Major NCDs are responsible for $85 \%$ of deaths and $70 \%$ of the disease burden in Europe and North America [18, 40, 41]. The costs for the care of the consequences of NCD present an enormous burden for the economy of the country in addition to the human suffering: even in those more affluent Member States where one sees downward trends in NCD mortality (primarily CVD, cancer, chronic obstructive pulmonary disease (COPD) and diabetes) [34-39]. Chronic disease places an enormous health and economic burden on the population of all Member States of the WHO European Region [39]. Multiple risk factors management is a critical area in the prevention and therapy of NCD and it has been shown to be effective in reducing mortality and disability mainly in CVD. It is well documented that NCDs have a significant impact on national economies by disabling and killing the working-age population [35-39]. The health systems of most developed countries are not adequately structured to respond to these emerging needs. The dissemination of information on the early diagnosis, treatment, and prevention of multiple risk factors in disease in many countries, have multiple barriers. These barriers are linked to a lack of integrated country-specific policies. Majority of the NCDs (as CVD, obesity, diabetes, COPD and some tumours) burden on lives and economy can be decreased by appropriate integrated approaches to health policies applied to: individual risk reduction (aimed at high-risk individuals), population risk reduction (aimed at social determinants), rational use of health services (by empowering primary health care), and referral system support and help from non-government organizations.

\section{NUTRITION AND EPIDEMIOLOGICAL TRANSITION}

The emergence of chronic diseases in most developing countries, in the last few decades is an example of epidemiological transition from undernutrition to overnutrition, because in 1950s in developed countries and in 1970s in developing countries, CVD and diabetes mellitus were least common $[1-4,14,20]$. NCDs develop in association with economic development in the country, first they increase among higher social classes, such as is in lower-middle and upper-middle-income countries; India, China and Russia respectively. Soon after learning the method of prevention, there is a decrease in risk of NCDs among higher social classes, and the risk concentrates among lower social classes, as in the developed countries [17, 19, 20]. The impact of NCDs, in particular CVD, was examined on 5 countries and reported that NCDs could have a serious effect on human and national development [11, 12]. The total number of years of productive life lost for the five countries in people aged 35 to 64 years would increase from 20.6 million in 2000 to 33.7 million in 2030. The World Health Organization estimated full-income losses due to heart disease, stroke and diabetes mellitus in 9 countries and found that these conditions were responsible for huge amounts of national income [3-8]. In developed countries, poor health policies based on market forces may increase the susceptibility of the lower social classes to NCDs [37-39]. These risk factors are amplified by stress, higher levels of environmentally induced risk behaviours, and limited access to high quality and affordable health care and healthy diet and lifestyle. In these countries, people with NCD, particularly CVD, are protected by social security systems and insufficient market-oriented health insurance, which enables them to buy necessary health care for treatment of diseases without any consideration for prevention of risk factors resulting in emergence of NCDs. In developing countries, the health insurance systems are just developing and the cost of care for CVD are borne individually hence treatment remains incomplete and most families spend out their resources leading to poverty [34-42]. The connection between lower socioeconomic status and NCDs extends beyond prevention and includes health education and its implementation by policy makers. In brief, epidemiological evolution of NCDs in developing populations, may have six stages of transition, characterized by indices of acculturation, 
urbanization, affluence, saturated fat, w- 6 fat and trans fat intakes, salt intake and tobacco consumption [39, 40]. A sedentary lifestyle, night shift work and psychological stress appear to play important roles during various stages of transition. The prevalence of obesity, metabolic syndrome, CVD and diabetes mellitus initially show an increase with a rise in these risk factors, which may show a decrease after learning the method of prevention, provided the health care is not under control of the market forces $[2,14,26,32,33,42]$.

\section{NUTRITION AND NONCOMMUNICABLE DISEASES}

Modern man appears to live in an environment that completely differs from that which his genetic constitution was originally selected. Our genes appear to be similar to the genes of our ancestors during the Paleolithic period 40,000 years ago, the time when our genetic profile was established [23-25]. However, it was only during the last 100 years that dietary intakes and lifestyles have changed significantly, causing increased intakes of refined carbohydrates, saturated fatty acids (SFA), trans fat, and w-6 fat and decreased intakes of $\omega-3$ fatty acids, from grain-fed cattle tamed at farm houses rather than meat from hunted free-roaming animals [23-25]. The food and nutrient intakes among hunter-gatherers during the Paleolithic period comprised fruits, vegetables, seeds, whole grains, egg, fish and wild animal meat which were low in w- 6 and high in w-3 fatty acids along with antioxidants, vitamins and minerals. In comparison to modern diets, there is a marked reduction in consumption of $\omega-3$ fatty acids, vitamins, minerals and proteins, and a significant increase in intakes of carbohydrates (mostly refined), fats (saturated and unsaturated trans fats, linoleic acid) and salt in the modern diets [1-4, 23$25,42]$. The high cardiovascular mortality in Eastern Europe and all other developing countries has often been attributed to poor diet, but individual-level data on nutrition in the region are generally not available [39, 41]. In one study, the methods of dietary assessment and presentation of preliminary findings on food and nutrient intakes in large general population samples in the Eastern Europe are reported [42]. The HAPIEE (Health, Alcohol and Psychosocial factors In Eastern Europe) study examined random samples of men and women aged 45-69 years at baseline in Novosibirsk (Russia), Krakow (Poland) and six Czech urban centres in 2002-2005. Diet was assessed using a food frequency questionnaire (at least 136 items); complete dietary information was available for 26,870 persons. Total energy intakes among men ranged between 8.7 MJ in the Czech sample and 11.7 MJ in the Russian sample, while among women, energy intakes ranged between 8.2 MJ in the Czech sample and 9.8 MJ in the Russian sample. A Healthy Diet Indicator (HDI), ranging from a score of 0 (lowest) to 7 (highest), was developed using the World Health Organisation's (WHO) guidelines for the prevention of chronic diseases [3-8]. The mean HDI scores were low, ranging from 1.0 $(\mathrm{SD}=0.7)$ among the Polish subjects to $1.7(\mathrm{SD}=0.8)$ among the Czech females. Very few subjects met the WHO recommended intakes for complex carbohydrates, pulses or nuts; intakes of saturated fatty acids, sugar and protein were too high. Only $16 \%$ of Polish subjects met the WHO recommendation for polyunsaturated fat intake. Consumption of fruits and vegetables was lower than recommended, especially among those Russian subjects who were assessed during the low intake season. Fewer than $65 \%$ of subjects consumed adequate amounts of calcium, magnesium and potassium, when compared with the United Kingdom's Reference Nutrient Intake. This first large scale study of individual-based dietary intakes in the general population in Eastern Europe (and beyond) implies that intakes of saturated fat, sugar and complex carbohydrates are a cause for concern in relation to NCDs [26, 41, 42]. WHO, International College of Cardiology and International College of Nutrition have been emphasizing for the last two decades about the role of diet in the development and prevention of NCDs [1-4, 19]. Recent studies indicate that a prudent dietary pattern, similar to a Mediterranean-style diet may be protective against NCDs [23-25]. Cohort studies and meta-analysis of studies showed that a fruit and vegetable enriched diet can protect against myocardial infarction and modulate microvascular function [43-47]. Fig. (4) demonstrates the lower risk associated prospectively with a Mediterranean diet, the paper by Sofi et al., [56] is well presented and heterogeneity amongst the selected studies is very low as seemingly is any publication bias: this study is well conducted. The beneficial effects of the Paleolithic prudent dietary pattern may be because of low w- 6 fatty acids and high content of alpha-linolenic acid (ALA), antioxidants, flavonoids, vitamins and carotinoids present in the diet [25]. Omega-3 fatty acids, such as alpha-linolenic acid (ALA), is rich in mustard oil, walnuts, green leaves, whole grains, and seeds and eicosapentaenoic acid (EPA) and docosahexaenoic acid (DHA) are rich in fish and fish oil and can be beneficial in microcirculation and myocardial infarction [48-52]. Apart from cohort studies, randomized, controlled intervention trials also confirm that a Paleolithicstyle diet can cause significant decline in morbidity and mortality due to cardiovascular events which may be because of the w-3 fatty acids present in such diet [53-60]. Majority of these studies were conducted when thrombolytic and angioplasty were not freely available for the treatment of acute coronary syndrome (ACS) $[57,58]$. Since thrombolytic is available now in developing countries, it is not possible to conduct such studies again to demonstrate the role of diet in the prevention of ACS. A recent study reported that one microRNA in particular, MIR168a, which is highly enriched in rice, was found to inhibit a protein that helps remove low-density lipoprotein (LDL) from the blood, suggesting that microRNAs can influence gene expression across kingdoms [61].

\section{EPIDEMIOLOGICAL STUDIES ON DIET AND NCDS}

Epidemiological studies indicate that a prudent dietary pattern characterized with fruit, vegetable, legume and whole grain intake appears to be protective [43-50]. The protective effects of prudent dietary patterns appear to be due to a low $\mathrm{w}-6 / \mathrm{w}-3$ ratio of such diets in conjunction with antioxidants, vitamins as well as essential and nonessential amino acids. In one cross-sectional survey among 6940 subjects, above 25 years of age, fruit, vegetable and legume intake were inversely associated with risk of pre-hypertension and hypertension in five Indian cities [14]. This study was conducted during 1993 to 1996 in India when w-6/w-3 ratio of fatty acids of the diet was increasing [1, 40] due to 
increased consumption of sunflower oils, soya bean oil and corn oil. A case-control study by Gramenzi and coworkers demonstrated for the first time that a Mediterranean-style diet was protective against acute myocardial infarction [51]. A meta-analysis of cohort studies, included a total 278,456 subjects $(9,143$ events) with a median follow up of 11 years. Those subjects who consumed more than 5 servings of fruits and vegetables per day, the relative risk was $0.83(0.77-0.89$, $\mathrm{P}<0.0001)$. The study showed that increased consumption of fruits and vegetables, less than 3 to more than 5 servings/day is related to a $17 \%$ reduction in the risk of CAD.

The association of dietary patterns with risk of acute coronary syndrome (ACS) was examined in the INTERHEART study, involving participants from 52 countries [49]. The score for prudent dietary pattern was inversely associated with risk of ACS and a significant positive relationship between the Western pattern score was observed. Oriental dietary pattern had a neutral effect. The authors reported that $30 \%$ of myocardial infarctions could be explained by unhealthy diets in this study.

A large, prospective, observational study [46] comprising of 72,113 nurses who were free of NCDs identified 2 dietary patterns; prudent and Western from available dietary data. The Western dietary pattern was characterized with high intake of processed meat, red meat, refined grains, French fries, sweets and desserts whereas prudent dietary pattern characterized with high intake of vegetables, fruits, legumes, fish, poultry and whole grains. After 18 years of follow up, 6011 deaths occurred; cancers 3,319 (52\%), CVDs 1154 $(19 \%)$ and $29 \%(n=1,154)$ due to other causes. Adherence to prudent diet was associated with $17 \%$ lower risk of total mortality, a $28 \%$ lower risk of CVD mortality and $30 \%$ lower risk due to non-CVD, non-cancer causes. Increased intake of Western type of diet caused greater total mortality; CVD mortality $22 \%$, cancer mortality $16 \%$ and deaths from non CVD and non-cancer causes $31 \%$. Deaths thus were increased as adherence to prudent diet decreased and adherence to the Western diet increased.

\begin{tabular}{|c|c|c|c|c|c|}
\hline Study & & & & Weight & Relative Risk (95\%) \\
\hline Trichopoulou (1995) & & - & & 0.3 & $0.69(0.48,0.99)$ \\
\hline Kouris-Blazos (1999) & & & & 0.2 & $\mathbf{0 . 7 9}(0.50,1.25)$ \\
\hline Lasheras (2000) & & & & 0.1 & $0.48(0.22,1.03)$ \\
\hline Knoops (2004) & & $\rightarrow$ & & 7.9 & $\mathbf{0 . 8 8}(0.82,0.94)$ \\
\hline Trichopoulou (2005) & & & & 14.7 & $0.93(0.89,0.97)$ \\
\hline Lagiou(2006) & & & & 3.2 & $0.93(0.83,1.04)$ \\
\hline Mitrou (M) (2007) & & & & 37 & $0.92(0.91,0.94)$ \\
\hline Mitrou (F) (2007) & & & & 30.7 & $0.93(0.91,0.95)$ \\
\hline Trichopoulou (2009) & & - & & 6.1 & $\mathbf{0 . 8 6}(0.80,0.93)$ \\
\hline Total $(95 \% \mathrm{Cl})$ & & 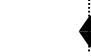 & & 100 & $0.92(0.90,0.94)$ \\
\hline 0.4 & 0.6 & 0.8 & 11.2 & 1.4 & \\
\hline
\end{tabular}

Fig. (5). Forest plot of the association between a 2-point increase of adherence score to the Mediterranean diet and the risk of all-cause mortality. The center of each square indicates the relative risk of the study, and horizontal lines indicate $95 \%$ CIs. The area of the square is proportional to the amount of information from the study. The diamond indicates pooled estimates. (Sofi et al. 2010) [56].

There is evidence that Western type of diet has adverse effects whereas Mediterranean diet, Indo-Mediterranean diet, Japanese diet and vegetarian diet of Europeans $\left(7^{\text {th }}\right.$ day Adventist) may be protective [47-64]. The above studies indicate a consistent association between Western dietary pattern; salty snacks, refined starches, fried foods, sweets and desserts and low in fruits and vegetables with risk of CAD and other NCDs in various regions of the world emphasizing adverse effects of globalization on human nutrition and NCDs risk [44-50]. Further studies suggest that the current trend of dietary convergence toward a typical Western type dietcharacterized with high $\mathrm{w}-6 / \mathrm{w}-3$ ratio of fatty acids, and low nutrient density, may be a risk factor for the globalization of obesity and NCDs [36-43]. A recent meta-analysis included 7 prospective studies published in the past 2 y that were not included in the previous meta-analysis (1 study for overall mortality, 3 studies for cardiovascular incidence or mortality, 1 study for cancer incidence or mortality, and 2 studies for neurodegenerative diseases) [56]. These recent studies included 2 health outcomes not previously investigated (i.e., mild cognitive impairment and stroke). The meta-analysis for all studies with a randomeffects model that was conducted after the inclusion of these recent studies showed that a 2-point increase in adherence to the Mediterranean diet was associated with a significant reduction of overall mortality [relative risk $(\mathrm{RR})=0.92 ; 95 \%$ CI: $0.90,0.94]$, cardiovascular incidence or mortality $(\mathrm{RR}=$ 0.90 ; 95\% CI: $0.87,0.93$ ), cancer incidence or mortality (RR $=0.94 ; 95 \%$ CI: $0.92,0.96$ ), and neurodegenerative diseases $(\mathrm{RR}=0.87 ; 95 \% \mathrm{CI}: 0.81,0.94)$. The meta-regression analysis showed that sample size was the most significant contributor to the model because it significantly influenced the estimate of the association for overall mortality. This meta-analysis confirms, in a larger number of subjects and studies, the significant and consistent protection was provided by adherence to the Mediterranean diet in relation to the occurrence of major chronic degenerative diseases (Fig. 5). 


\section{INTERVENTION TRIALS ON PALEOLITHIC-STYLE DIET AND MORTALITY}

Cohort studies provide an association of diet with risk of CVDs and deaths which do not provide a proof that it is the cause of the problem. Therefore, randomized, controlled intervention trials are necessary to provide scientific rigour that diet has a role in the prevention of NCDs [53-60]. Intervention trials, using the whole diet approach so far conducted are also in line with this epidemiological evidence. The effect of Paleolithic-style diet was examined in patients ( $\mathrm{n}=204$ intervention group, $\mathrm{n}=202$ control group) with acute coronary syndromes, which showed significant decline in total cardiac events as well as in total mortality after 6 weeks and the benefit continued after one year [57, 58]. Further follow up for 2 years in this study [59] is different from the published work, because it emphasis on the Paleolithic dietary patterns and ALA content of the diet to be responsible for the significant greater survival in the intervention group compared to control group. Dietary patterns before entry to the study showed higher w- $6 / \mathrm{w}-3$ ratio of 32.5 in the diets of both the groups. Intervention group A was advised a Paleolithic-style diet with w- $6 / \mathrm{w}-3$ fatty acid ratio of 4.3 compared to standard diet group with ratio of 20. Dietary adherence was excellent (Table 1). After a follow up of 2 years, total mortality was significantly declined in the Paleolithic-style diet group compared to control group (Table 2). The mortality was lowest among subjects with w-6/w-3 ratio of less than 5 which showed graded increase with increase in the fatty acid ratio in both the groups. In the Lyon Diet Heart Study [53], 605 patients who had a myocardial infarction were randomly assigned to a 'Mediterranean-style' diet or a control diet resembling the American Heart Association Step I diet. The Mediterranean diet model supplied $30 \%$ of energy from fats and $<10 \%$ of energy from saturated fatty acids, whereas the intake of $18: 3$ (n-3) (-linolenic acid) provided $>0.6 \%$ of energy. After a mean follow-up of 27 months, the risk of new acute myocardial infarction and episodes of unstable angina was reduced by $\sim 70 \%$ by the Mediterranean diet [53]. Moreover, total mortality was also reduced by $70 \%$. Long-term followup for 4 years also showed that the beneficial effects of diet were continued. Singh et al., [54] tested an 'IndoMediterranean diet' in 1000 patients in India, with existing coronary disease or at high risk for coronary disease. Half of the patients ( $\mathrm{n}=499$ vs. 501 ) were administered a diet rich in fruits, vegetables, whole grains, walnuts, mustard and soy bean oil as a source for w-3 fat and the rest i.e. 501 patients, were advised to take prudent diet advised by the National Cholesterol Education Program Step 1 diet in 1988. At the end of 2 year follow-up, the Paleolithic-style diet group consumed significantly more fruits, vegetables and legumes than did the control group $(537 \pm 127$ vs. $231 \pm 19$ g/day, $\mathrm{p}<0.001)$ as well as more mustard and soy bean oil $(31 \pm 6.5$ vs. $15.2 \pm 5.5 \mathrm{~g} / \mathrm{day})$. The mean intake of ALA was over twofold greater in the Paleolithic-style diet group compared to control group ( $1.8 \pm 0.4$ vs. $0.8 \pm 0.2 \mathrm{~g} / \mathrm{day}, \mathrm{p}<0.001)$. The $\mathrm{w}-6 / \mathrm{w}-3$ ratio of fatty acids was slightly higher at baseline in the intervention group than in the control group $(39 \pm 12 \mathrm{vs}$. $34 \pm 10$ ) yet both these figures are extremely high, reflecting a diet with a very high w-6 content yet low w-3 [50]. At the end of two years follow up, this ratio showed a marked decline in the intervention group, which was greater than that observed in the control group consuming control diet ( $9.1 \pm 12$ vs. $21 \pm 10, \mathrm{p}<0.001)$. The study end points were; significant decline in the total cardiac events, sudden cardiac death and nonfatal infarction in the intervention group compared to the control group (Table 3). The diet and reinfarction trial [60] showed that modest intake of fish, 2 servings per week can cause $29 \%$ decrease in total mortality and cardiovascular mortality. Since no benefit was observed in nonfatal infarction, the authors concluded that w-3 fatty acids may have prevented ventricular fibrillation by altering cardiomyocyte cell membrane phospholipids. Esposito et al., [62] randomized 180 patients (99 men, 81 women) with metabolic syndrome to a Mediterranean-style diet, characterized with whole grains, vegetables, fruits, nuts and olive oil vs. a cardiac-prudent diet with fat intake $<30 \%$. After a follow up of 2 years, subjects in the intervention diet showed greater weight loss, had lower C-reactive protein, and proinflammatory cytokine levels, had less insulin resistance, as well as lower total cholesterol and triglycerides and higher HDL cholesterol. The prevalence of metabolic syndrome was reduced to one half. The Japan Public Health Centre based study [63] showed that eating more w-3 fatty acids by increased intake of fish was associated with significant reduction in cardiovascular disease and cardiac mortality. Yokoyama et al., investigated the effects of EPA on major coronary events in hypercholesterolemic patients in a randomized open label, blinded analysis [64]. Patients were randomly assigned to receive either $1800 \mathrm{mg}$ of EPA with statin or statin only in a 5-year follow up. The results showed that EPA is a promising treatment for prevention of major coronary events, and especially nonfatal coronary events, in Japanese hypercholesterolemic patients. This is a very important finding because the Japanese already have a high fish intake. Iso et al., further supported these findings in his study and compared a modest fish intake of once a week or with about $20 \mathrm{~g} / \mathrm{d}$ [64]. A higher intake of fish was associated with substantially reduced risk of coronary artery disease, primarily nonfatal cardiac events, among middleaged persons.

\section{MECHANISMS AND INTERACTIONS OF RISK FACTORS}

Diet can also provide beneficial effects by its influence on gut- brain-liver axis and related gut hormones; leptin, ghrelin, incretins, BDNF, cholecystokinins, insulin and enzymes, leading to decline in NCDs [65-67]. High w-3 fatty acids in the diet can modulate depression and it could be important in the nerve regeneration [68, 69]. Proinflammatory foods can enhance inflammation which may be damaging to adipocyte, endothelial cells, mononuclear cells, smooth muscle cells and beta cells of pancreas which are very susceptible for dysfunctioning, if there is deficiency of w-3 fatty acids in the phospholipids of the cell membranes [2325]. Leptin has been found to have a profound role in the regulation of whole-body metabolism by stimulating energy expenditure, inhibiting food intake and restoring euglycemia, however, in most cases of obesity, leptin resistance limits its biological efficacy. In contrast to leptin, adiponectin secretion is often diminished in obesity. Adiponectin acts to increase insulin sensitivity, fatty acid oxidation, as well as energy expenditure and reduces the production of glucose by the liver. Resistin and retinol binding protein- 4 are less well 
Table 1. Effect of w-3 Fatty Acid Rich Paleolithic-Style Diet in Patients with Acute Myocardial Infarction

\begin{tabular}{|c|c|c|c|c|}
\hline \multirow[b]{2}{*}{ Foods and nutrients(g/day) } & \multicolumn{2}{|c|}{ Paleolithic-Style Diet Group $(n=204)$} & \multicolumn{2}{|c|}{ Standard Diet Group $(n=202)$} \\
\hline & 4-7 days & After 1 years & 4-7 days & After 1 years \\
\hline Fruits and vegetables (g/ day) & $508.4 \pm 28.66 * *$ & $575 \pm 91.4 * *$ & $254.4 \pm 17.2$ & $220.5 \pm 19.6$ \\
\hline Potato, radish, & $60.5 \pm 6.8$ & $115 \pm 12.7^{* *}$ & $72.0 \pm 12.5$ & $155.6 \pm 32.5$ \\
\hline Legumes and pulses (g/day) & $80.5 \pm 6.6 * *$ & $95.0 \pm 8.9 * *$ & $52.5 \pm 4.6$ & $45.6 \pm 5.6$ \\
\hline Almonds and walnuts (g/day) & $82.4 \pm 5.7 * *$ & $75.5 \pm 5.2 * *$ & - & - \\
\hline Fish(g/day)) & $52.5 \pm 6.5 * *$ & $22.4 \pm 4.1 * *$ & $20.2 \pm 3.1$ & $10.5 \pm 3.5$ \\
\hline Chicken(g/Day) & - & $10.2 \pm 3.2 *$ & $76.2 \pm 6.5$ & $66.5 \pm 10.5$ \\
\hline Mustard or soybean oil(g/day) & $18.4 \pm 3.9^{*}$ & $31.5 \pm 5.5 * *$ & $10.5 \pm 2.3$ & $6.8 \pm 2.8$ \\
\hline Butter or clarified butter(g/day)) & $2.5 \pm 0.6^{* *}$ & $3.3 \pm 0.71 *$ & $10.5 \pm 2.6$ & $12.6 \pm 3.5$ \\
\hline Skim milk (ml day-1) & $161.2 \pm 12.0$ & $152 \pm 14.5^{*}$ & $150.2 \pm 8.0$ & $165.5 \pm 16.1$ \\
\hline Wheat chapatti (g/day) & $5.5 \pm 1.6 * *$ & $30.6 \pm 5.5$ & $50.6 \pm 6.6$ & $55.6 \pm 7.8$ \\
\hline Bread, biscuits (g/day)) & $10.6 \pm 2.2 *$ & $25.5 \pm 6.2 * *$ & $230.6 \pm 20.1$ & $212.2 \pm 18.1$ \\
\hline Rice and wheat cereals(g/day)) & $25.6 \pm 2.4$ & $30.6 \pm 5.5$ & $30.2 \pm 3.1$ & $35.6 \pm 4.8$ \\
\hline Honey or raisins(g/day)) & $2.6 \pm 0.8$ & $5.5 \pm 1.2$ & - & - \\
\hline Sugar(g/day)) & $16.4 \pm 3.7^{*}$ & $12.6 \pm 3.4^{*}$ & $25.5 \pm 5.4$ & $30.5 \pm 7.6$ \\
\hline Total Adherence score (\%) & $65.2 \pm 17.2$ & $63.9 \pm 14.8 *$ & $123.0 \pm 30.0$ & $71.0 \pm 30.0$ \\
\hline Total foods (g/day) & $1027 \pm 232$ & $1184.6 \pm 254$ & $983.4 \pm 213$ & $862 \pm 204$ \\
\hline
\end{tabular}

$\mathrm{P}$ values, and Mean \pm standard deviation were obtained by comparison of intervention and control groups during 1 week and after 1 year. $*=\mathrm{P}<0.05$, $* * \mathrm{P}<0.01$. Singh $e t$ al., $(59)$.

Table 2. Numbers and Rate Ratios for End Points in the Paleolithic-Style Diet Group and Standard Diet Group after 2 Years of Follow up

\begin{tabular}{|l|l|l|l|}
\hline Events & Paleolithic-Style Diet (n=204) & Control Diet (n=202) & Adjusted Rate Ratio (95\% Confidence Interval) \\
\hline \hline Total Cardiac mortality & $27(13.2)^{* *}$ & $45(22.3)$ & $0.59(0.52-0.67)$ \\
\hline Fatal myocardial infarction & $18(8.8)^{* *}$ & $27(13.3)$ & $0.66(0.61-0.73)$ \\
\hline Sudden cardiac death & $9(4.4)^{*}$ & $18(8.9)$ & $0.50(0.38-0.73)$ \\
\hline Total cardiovascular mortality & $30(14.7)^{* *}$ & $50(24.7)$ & $0.50(0.42-0.59)$ \\
\hline Total mortality & $30(14.7)^{* *}$ & $51(25.2)$ & $0.59(0.51-0.67)$ \\
\hline
\end{tabular}

Values are number $(\%), * *=\mathrm{p}<0.001, *=\mathrm{p}<0.01$, Singh et al., (59).

Total deaths; adjustment made for base line age, gender, body mass index, cholesterol and blood pressure.

Table 3. Total Cardiovascular Events in the Indo-Mediterranean-Style Diet and Control Group

\begin{tabular}{|l|l|l|}
\hline Events & Indo-Mediterranean Diet (n=499) & Standard Diet (n=501) \\
\hline \hline Non fatal myocardial infarction & $21(4.2 \%)^{*}$ & $43(8.6 \%)$ \\
\hline Fatal myocardial infarction & $12(2.4 \%)$ & $17(3.4 \%)$ \\
\hline Sudden cardiac death & $6(1.2 \%)$ & $16(3.2 \%)$ \\
\hline Total cardiac events & $39(7.8 \%)^{* *}$ & $76(15.2 \%)$ \\
\hline Stroke & $7(1.4 \%)$ & $13(2.6 \%)$ \\
\hline Stroke death & $2(0.4 \%)$ & $3(0.6 \%)$ \\
\hline Total cardiovascular events & $48(9.6 \%)^{* *}$ & $92(18.3 \%)$ \\
\hline Total deaths & $24(4.8 \%)$ & $38(8 \%)$ \\
\hline
\end{tabular}

Values are number $(\%), *=\mathrm{P}<0.01, * *=\mathrm{P}<0.001$, Singh et al., 2002, (54). 
described. Their expression levels are positively correlated with adiposity and they are both implicated in the development of insulin resistance. More recently it has been acknowledged that macrophages are an important part of the secretory function of adipose tissue and the main source of inflammatory cytokines, such as TNF alpha and IL-6. An increase in circulating levels of these macrophage-derived factors in obesity leads to a chronic low-grade inflammatory state that has been linked to the development of insulin resistance and diabetes Depression may predispose glycemia, resulting in release of superoxide anion, which can damage the mononuclear cells resulting in increased levels of proinflammatory cytokines. These cytokines; tumor necrosis factor (TNF)-alpha, interleukin (IL)-6, IL-18 and C-reactive proteins are proinflammatory which can damage the endothelium causing endothelial dysfunction and other concerned organs of the body resulting in NCDs. A crosssectional sample of 132 eligible participants who had recovered from major depression (mean \pm SD age: $67.8 \pm 6.6$ y) were enrolled from outpatient psychiatric services [68]. A series of cognitive tests and a structured questionnaire were administered. Fasting blood samples were collected for n-3 PUFA measurements. Higher EPA and total n-3 PUFA concentrations and a lower ratio of arachidonic acid to EPA in erythrocyte membranes were associated with a higher cognitive composite score: independent of age and sex, but no longer significant after adjustment for education. No associations were found with plasma concentrations of any fatty acid. Considering individual cognitive tests, the strongest and most consistent correlations were found between immediate recall and concentrations of total n-3 PUFAs and $\alpha$-linolenic acid (ALA) in erythrocytes, which were observed only in participants with recurrent depression. Total erythrocyte n-3 PUFA concentrations were positively associated with cognitive function, particularly immediate recall, in older people with previous depression. Lower concentrations of n-3 PUFAs or ALA in erythrocyte membranes may be good predictors for cognitive impairment in older people with previous recurrent depression. A recent study examined the neuroprotective and pro-regenerative potential of omega-3 polyunsaturated fatty acids (PUFAs) in peripheral nerve injury [69]. Subject mice (empathy nomenclature for observer learning but without performing an operant task) that express the fat- 1 gene (fat-1) encoding for omega-3 fatty acid desaturase, which leads to an increase in endogenous omega-3 PUFAs and a concomitant decrease in omega-6 PUFAs, were studied in contrast to wild-type mice (wild-type). Dorsal root ganglion neurons from wildtype or fat-1 mice were subjected to a mechanical strain or hypoxic injury, and cell death was assessed using ethidium homodimer-1 labeling. The fat-1 background appears to confer robust neuroprotection against both injuries. Early functional and morphological changes in wild-type and fat-1 mice after a sciatic nerve crush were examined. An accelerated functional recovery $7 \mathrm{~d}$ after injury was seen in fat-1 mice when assessed. The injury-induced expression of cyclic AMP-dependent transcription factor (ATF-3) was decreased in the dorsal root ganglion of fat- 1 mice, whereas the axons detected $6 \mathrm{~mm}$ distal to the crush were increased. Fat-1 animals also had some protection against muscle atrophy after injury. Researchers concluded that a higher endogenous omega-3 PUFA could lead to beneficial effects after a peripheral nerve injury. Chronobiology is the only science, which establishes a clear relation between brain and body functions. A chronobiological approach has also been suggested for prevention of NCDs by several experts under the leadership of Franz Halberg [70-72]. Mind-brain-bodygene framework, including the role of chrononutrition, is probably implicated in the genesis of NCDs including of functional gastrointestinal diseases (FGIDs). Emphasis was placed on psychosocial dysregulation, the bridging of the Cartesian Gap, and chronobiology viz. the way circadian and other rhythmic structures of the brain, e.g. suprachiasmatic nucleus, and gastrointestinal tract interact partially explaining the phrase "we are what and when we eat". Chronobiological concepts of strain and stress in the context of sensory pain and the time-qualified network of gut hormones and neuropeptides are discussed for melatonin, serotonin, ghrelin, leptin, vasoactive intestinal peptide, neuropeptide $Y$, orexins and others [72]. The human brain is quite rich in long chain polyunsaturated fatty acids (PUFA) such as arachidonic acid, eicosapentaenoic acid(EPA) and docosahexaenoic acid(DHA) [23-25]. These fatty acids are neuroprotective and constitute $30 \%$ to $50 \%$ of the total fatty acids in the brain, where they are predominantly associated with membrane phospholipids [25]. Therefore, if there is a deficiency of long chain PUFA, especially during the critical period of brain growth, from the third trimester to infant age (2 years), it may cause increased levels of TNF-alpha which is known to damage the neurons [23-25]. TNF-alpha may also damage the suprachiasmatic nucleus, pineal and pituitary glands, olfactory bulb and the hypothalamus, the last three are rich in insulin receptors which are important in the pathogenesis of NCDs. However, TNF-alpha could be decreased by longchain PUFA, especially, n-3 fatty acids and may be enhanced due to their deficiency and due to excess of w- 6 fatty acids [23]. It seems that TNF-alpha may participate in the pathogenesis of NCDs by two mechanisms; primarily by inducing insulin resistance and secondarily by interfering with functions of the ventromedial hypothalamus. Potentially protective content of these functional foods include ALA, EPA, DHA, folate, magnesium, calcium, potassium, fibre, vitamin $\mathrm{E}$, carotenoids, arginine, taurine, cysteine, oleate and favorable lysine to arginine ratio and methionine to arginine ratio. These nutrients are important in the cardiomyocyte and arterial cell functions which are determinants of CVDs. The lysine to arginine ratio is being potentially involved in atherogenesis, and the methionine to arginine ratio is important for endothelial function because arginine is the precursor of NO which protects the endothelium and methionine is the precursor of homocysteine that is known to cause endothelial damage. Folic acid is protective because it antagonizes the homocysteines. Calcium/magnesium ratio indicating high magnesium is also protective to cardiomyocyte and endothelial cells [73]. These findings indicate that it is the tissue which is the main issue in the pathogenesis and prevention of CVDs. If the tissue concentration of $\mathrm{w}-6 / \mathrm{w}-3$ ratio is $1: 1$ along with other nutrients in proper ratio, high LDL cholesterol (unoxidised) would be neutral without any evidence of endothelial 
dysfunction. This concept has become more relevant because microRNA have been demonstrated in the blood and milk after feeding of rice to experimental animals [61]. Therefore, apart from diet, a causal relationship between nutrients exists; viz. magnesium, vitamin $\mathrm{D}$ with diabetes mellitus and CVDs has been suggested, but little research has been conducted on this subject $[73,74]$. Glucose tolerance status and serum vitamin D, have been obtained in 263 subjects. Various demographic variables such as gender, age, season, resident area, physical activity, smoking, alcohol, marital status, education and occupation were associated with serum 25-hydroxyvitamin D concentrations. After adjusting for these variables as confounders, 25-hydroxyvitamin D concentrations in subjects with diabetes were significantly lower than those in subjects with normal glucose tolerance and those with impaired fasting glucose $(\mathrm{P}=0.005)$. Compared with the $\geq 75 \mathrm{nmol} / 1$ subgroup of serum 25 -hydroxyvitamin $\mathrm{D}$ concentration, the odds ratios and $95 \%$ confidence intervals for diabetes mellitus were 1.206 (95\% CI 0.948 $1.534)$ in the 50 to $74 \mathrm{nmol} / 1$ subgroup, 1.339 (1.051-1.707) in the 25 to $49 \mathrm{nmol} / 1$ subgroup and 1.759 (1.267-2.443) in the $<25-\mathrm{nmol} / 1$ subgroup. Compared with the serum $\geq$ $75 \mathrm{nmol} / 1$ 25-hydroxyvitamin D subgroup, serum insulin and homeostasis model assessment $2 \% \mathrm{~B}$, a marker of insulin secretory capacity, were significantly higher, and homeostasis model assessment $2 \% \mathrm{~S}$, a marker of insulin sensitivity, was significantly lower in the $<25$ and 25 - to $49-\mathrm{nmol} / 1$ serum 25-hydroxyvitamin $\mathrm{D}$ subgroups than those in the other subgroups $(\mathrm{P}<0.001)$. The findings suggest that vitamin $\mathrm{D}$ deficiency, possibly involving altered insulin sensitivity, is associated with an increased risk for diabetes mellitus in the Korean population Vitamin D deficiency may also be a risk factor for metabolic syndrome and CVDs.

\section{PREVENTION OF NONCOMMUNICALE DISEASES}

International College of Nutrition and International College of Cardiology recognise that a small number of risk factors are common to major NCDs $[1,2]$. The simultaneous reduction of these common risk factors would reduce the major NCDs and improve public health. This concept emphasizes health promotion and disease prehabilitation through existing health care systems and the active participation of communities and of individual as well as active guidance from government and non-governmental organizations. However this concept should be first adopted in the Western world because the whole world generally follows what is happening in North America. The UN should lead to begin with, first in USA followed by European Union and then the rest of the world [21]. It should be re-emphasized that NCDs are not the problems associated with poverty, but due to lack of health education and wrong policies of the governments adopted in developed countries which are being followed by the developing countries. There is a need for UN-led team of organizations, to integrate interventions that are aimed at several risk factors within the country's healthcare system. This should be a comprehensive approach that combines various implementation strategies, including policy development, capacity building, partnership and information support at all levels. The aim should be to promote transversal health policies, including coordinated action by several sectors; development of inexpensive designer foods and crops, gyms and sports, banning of tobacco for human consumption, cheaper wines, more expensive other alcohol products, introduction of sports, yoga and meditation in schools as well as at the work place, to address major determinants of ill health that fall outside the ambit of the health sector. It may be important to combine health policy and high-risk strategies which would link the preventive action of various components of the healthcare system such as health promotion, public health services, primary care, and hospital care $[1,11,20]$. According to WHO, we know what works, we know what it costs and we know that all countries are at risk. We have an Action Plan to avert millions of premature deaths and help promote a better quality of life for millions more [5-9]. The 2008-2013 Action Plan for the Global Strategy for the Prevention and Control of NCDs was developed by WHO with Member States and is based on an overall strategy for the prevention and control of NCD or chronic diseases defined in March 2000 and defines the objectives for the period 2008-2013 and the actions to be implemented [5]. The Action Plan was endorsed at the Sixty-first World Health Assembly in May 2008 by delegates from 193 Member States. The document: explains the reasons for urgent action for the period 20082013 aimed at the growing burden of chronic diseases on public health; provides the political framework of Action Plan, including the requirement to report global progress in 2010 and 2012; presents the main global strategy for prevention and control of NCDs, which urges Member States to develop frameworks for national policy, to establish programs, and to share their experiences. The WHO global goal is to reduce chronic disease death rates by $2 \%$ per year over current trends [5] which is based on CAD trends in developed countries over the past 40 years and recent changes in middle-income countries in the Eastern Europe. It is possible that the WHO goal, if successful, can avert 36 million chronic disease deaths by 2015 , of which half would be due to CVDs $[1,5,13]$. Approximately one half of these deaths would be in subjects below 70 years, and $3 / 4$ of the averted deaths would be in Low- and middle- income countries. These benefits are likely to be translated into better quality of human development and decreased mortality in these countries [1-9]. The WHO Action Plan includes 6 specific objectives: to raise the priority given to chronic diseases in national and global development plans and strategies for integrating strategies of prevention and control into policies across all government departments to establish and to improve national policies and plans for the prevention and control of NCDs: to promote measures to reduce the major modifiable risk factors for chronic diseases: tobacco use, unhealthy diet, lack of exercise and abuse of alcohol to promote research for prevention and control of chronic diseases to promote partnerships for the prevention and control of chronic diseases: to monitor chronic diseases and their determinants and evaluate progress at the national, regional and global level [1-5]. These efforts are definitely commendable but have some limitations because a clear definition of healthy diet as well as stress and depression as a risk factor of chronic diseases using chronobiological approach have not been addressed, although the European Union has adopted FROM FARM TO FORK approach for health promotion [5-9]. 
International College of Nutrition and International College of Cardiology in their new guidelines [1] emphasize that eating $400 \mathrm{~g} / \mathrm{day}$ of fruits, vegetables and nuts and another $400 \mathrm{~g} /$ day of whole grains including legumes, in conjunction with canola oil/mustard or blended oil containing olive oil $+\mathrm{w}-3$ rich oil (flexed seed oil) may be protective against possibly NCDs. Further studies [75-82] also suggest the role of lifestyle factors in the prevention of NCDs.

\section{ACKNOWLEDGEMENTS}

Acknowledgements are due to International College of Nutrition and International College of Cardiology for their support for preparing this article.

\section{CONFLICT OF INTEREST}

Declared none.

\section{REFERENCES}

[1] Singh RB, De Meester F, Pella D, Basu TK, Watson R. Globalization of dietary wild foods protects against cardiovascular disease and all cause mortalities? A Scientific statement from the International College of Cardiology, Columbus Paradigm Institute and the International College of Nutrition. Open Nutra J 2009; 2: $42-5$.

[2] Singh RB, Pella D, Mechirova V, et al. Prevalence of obesity, physical inactivity and undernutrition, a triple burden of diseases during transition in a developing economy. The Five City Study Group. Acta Cardiol 2007; 62: 119-27.

[3] Joint WHO/FAO Expert Consultation. Diet, Nutrition and the Prevention of Chronic Diseases, WHO, Geneva, WHO Technical Report Series, 916, 2003.

[4] WHO Study Group. Diet, Nutrition and Prevention of Chronic Diseases, WHO, Geneva, 1990.

[5] World Health Organization. The 2008-2013 Action Plan for the Global Strategy for the Prevention and Control of Noncommunicable Diseases (Action Plan http://www.who.int/nmh/ Actionplan-PC-NCD-2008.pdf [Accessed January 2012].

[6] World Health Organization. Preventing Chronic Disease: A Vital Investment World Health Organization, Geneva, 2005.

[7] World Health Organization. Diet and Physical Activity: a public Health Priority. World Health Organization. Available at: http:/www.who. int/diet physical activity/en/ [Accessed 2012].

[8] World Health Organization. WHO frame work convention on tobacco control. Available at: http:/www.whoint/tobacco/ framework/en/ [Accessed January 2012].

[9] UN. Prevention and control of non-communicable disease. New York: United Nations, 2010. Available at: http://www.un.org/ $\mathrm{ga} / \mathrm{search} /$ view doc.asp?symbol=A\%2F64\%2FL.52\&Submit=Sear ch\&Lang=E [Accessed January 3, 2012].

[10] Rosenbaum L, Lamas D. Global Health: Facing a "Slow-motion disaster" -- the UN meeting on noncommunicable diseases. N Engl J Med 2011; 365: 2345-8.

[11] Beaglehole R, Bonita R, Alleyne G, et al. UN High-Level Meeting on Non-Communicable Diseases: addressing four questions. Lancet 2011; 378: 449-55.

[12] WHO. Mortality and burden of disease estimates for WHO Member States in 2008. Geneva: World Health Organization, 2010.

[13] Nabel EG, Braunwald E. A tale of coronary artery disease and myocardial infarction. N Engl J Med 2012; 366: 54-63.

[14] Singh RB, Fedacko J, Pella D, et al. Prevalence and risk factors of pre-hypertension and hypertension in five Indian cities. Acta Cardiol 2011; 66: 29-37.

[15] Singh RB, Fedacko J, Vargova V, et al. Singh's verbal autopsy questionnaire for assessment of causes of death, social autopsy, tobacco autopsy, and dietary autopsy based on medical records and interview. Acta Cardiol 2011; 66: 471-81.
[16] Singh RB, Singh V, Kulshrestha SK, et al. Social class and all cause mortality in the urban population of north India. Acta Cardiol 2005; 60: 611-7.

[17] Singh RB, Suh IL, Singh VP, et al. Hypertension and stroke in Asia: prevalence, control and strategies in developing countries for prevention. J Human Hyper 2000; 14: 749-63.

[18] Roger VL, Go AS, Lloyd-Jones DM, et al. On behalf of the American Heart Association Statistics Committee and Stroke Statistics Subcommittee. Heart disease and stroke statistics-2012 update: a report from the American Heart Association. Circulation 2012; 125: e2-220.

[19] Singh RB, Beegom R, Mehta AS, et al. Social class and coronary risk factors and undernutrition: a double burden of diseases among women in five Indian cities. Int J Cardiol 1999; 353: 154-65.

[20] Sergey C, Agarval R, Singh RB, Wilczynszka A, De Meester F. Can environmental factors predispose noncommunicable diseases? Open Nutra J 2011; 4: 45-51.

[21] Lee PT, Henderson M, Patel V. A UN summit on global mental health. Lancet 2010; 376: 516.

[22] Manderbacka K, Sund R, Koski S, Keskimäki I, Elovainio M. Diabetes and depression? Secular trends in the use of antidepressants among persons with diabetes in Finland in 19972007. Pharmacoepidemiol Drug Saf 2011; 20: 338-43.

[23] Simopoulos AP. The importance of the $\omega-6 / \omega-3$ fatty acid ratio in cardiovascular diseases and other chronic diseases. Exp Biol Med 2008; 233: 674-88.

[24] Simopoulos A. Essential fatty acids in health and chronic diseases. Am J Clin Nutr 1999; 70(Suppl 3): 560-69s.

[25] Toda E, Toru T, Singh RB, et al. Effects of Paleolithic-style diet with emphasis on $\omega-6 / \omega-3$ fatty acids ratio on coronary artery disease: the tissue is the issue. Am Med J 2012; (in press).

[26] Moscow Declaration. First Global Ministerial Conference on Healthy Lifestyles and Noncommunicable Disease Control nmh/events/ moscow_ncds_2011/conference_documents/moscow_; Moscow, Russia; April 28-28, 2011. Available at: http://www.who.int/ entity/nmh/events/moscow_ncds_2011/conference_documents/mos cow_declaration_en.pdf [Accessed January, 2012].

[27] UN. Prevention and control of non-communicable disease. NewYork: United Nations, 2010. Available at: http://www.un.org/ ga/search/view_doc.asp?symbol=A\%2F64\%2FL.52\&Submit=Sear ch\&Lang $=\mathrm{E}$ [Accessed January 3, 2012].

[28] Beaglehole R, Bonita R, Horton R, et al. For The Lancet NCD Action Group and the NCD Alliance. Priority actions for the noncommunicable disease crisis. Lancet 2011; 377: 1438-47.

[29] Mwatsama M. Raising the political priority of chronic diseases on the global health and development agenda. London: National Heart Forum 2010

[30] WHO. Global Status Report on noncommunicable diseases 2010. Geneva: World Health Organization 2011.

[31] Oberg M, Jaakkola MS, Woodward A, Peruga A, Prüss-Ustün A. Worldwide burden of disease from exposure to second-hand smoke: a retrospective analysis of data from 192 countries. Lancet 2011; 377: 139-46.

[32] Finucane MM, Stevens GA, Cowan MJ, et al. On behalf of the Global Burden of Metabolic Risk Factors of Chronic Diseases Collaborating Group (Body Mass Index). National, regional, and global trends in body-mass index since 1980: systematic analysis of health examination surveys and epidemiological studies with 960 country-years and 9·1 million participants. Lancet 2011; 377: 557-67.

[33] Danael G, Finucane MM, Lin JK, et al. On behalf of the Global Burden of Metabolic Risk Factors of Chronic Diseases Collaborating Group (Blood Pressure). National, regional, and global trends in systolic blood pressure since 1980: systematic analysis of health examination surveys and epidemiological studies with 786 country-years and 5.4 million participants. Lancet 2011; 377: 568-77.

[34] Gluckman P, Hanson M. Mismatch. Why our world no longer fits our bodies. Oxford: Oxford University Press 2006.

[35] Suhrcke M, Rocco L, McKee M, Mazzuco S, Urban D, Steinherr A. Economic consequences of non-communicable diseases and injuries in the Russian Federation. London: European Observatory on Health Systems and Policies 2007. 
[36] Mahal A, Karan A, Engelau M. The economic implications of noncommunicable disease for India. Washington: World Bank 2010.

[37] Adeyi O, Smith O, Robles S. Public policy and the challenge of chronic non-communicable diseases. Washington: World Bank 2007.

[38] Stuckler D. Population causes and consequences of leading chronic diseases: a comparative analysis of prevailing explanations. Milbank Q 2008; 86: 273-326.

[39] Abegunde DO, Mathers CD, Adam T, Ortegon M, Strong K. The burden and costs of chronic diseases in low-income and middleincome countries. Lancet 2007; 370: 1929-38.

[40] Gillum RF. The epidemiological evolution in pattern of cardiovascular diseases in blacks. N Engl J Med 1996; 335: 1597-99.

[41] Mesle F. Mortality in central and eastern Europe: long-term trends and recent upturns. Demogr Res 2004; 2: 45-70.

[42] Boylan S, Welch A, Pikhart H, et al. Dietary habits in three Central and Eastern European countries: the HAPIEE study. BMC Public Health 2009; 9: 439-45.

[43] Fung TT, Chiuve SE, McCullough ML, Rexrode KM, Logroscino $\mathrm{G}, \mathrm{Hu}$ FB. Adherence to DASH- style diet and risk of coronary heart disease and stroke in women. Arch Intern Med 2008; 168: 713-20.

[44] Knoops KTB, de Groot LC, Kromhout D, et al. Mediterranean diet, lifestyle factors and 10-year mortality in elderly European men and women. The HALE project. JAMA 2004; 292: 1433-9.

[45] Trichopolou A, Bamia C, Trichopolou D. Anatomy of health effects of Mediterranean diet. Greek EPIC prospective cohort study. BMJ 2009; 338: b2337.

[46] Heidemann C, Schulze MB, Franco OH, et al. Dietary patterns and risk of mortality from cardiovascular disease, cancer, and all causes in a prospective cohort of women. Circulation 2008; 118: 230-7.

[47] He FJ, Nowson CA, Lucas M, MacGregor GA. Increased consumption of fruit and vegetables is related to a reduced risk of coronary heart disease: meta-analysis of cohort studies. J Hum Hypertens 2007; 21: 717-28.

[48] Hu FB. Globalization of food patterns and cardiovascular disease risk. Circulation 2008; 118: 1913-4.

[49] Iqbal R, Anand S, Ounpuu S, et al. Dietary patterns and the risk of acute myocardial infarction in 52 countries. Circulation 2008; 118 : 1929-37.

[50] Renaud S, de Lorgeril M, Delaye J, et al. Cretan Mediterranean diet for prevention of coronary heart disease. Am J Clin Nutr 1995; 61(6 Suppl): 1360S-7S.

[51] Gramenzi A, Gentile A, Fasoli M, Negri E, Parazzini F, La Vecchia C. Association between certain foods and risk of acute myocardial infarction in women. BMJ 1990; 300: 771-3.

[52] McCall DO, McGartland CP, McKinley MC, et al. Dietary intake of fruits and vegetables improves microvascular function in hypertensive subjects in a dose-dependent manner. Circulation 2009; 119: 2153-60.

[53] de Lorgeril M, Renaud S, Mamelle N, et al. Mediterranean alphalinolenic acid-rich diet in secondary prevention of coronary heart disease. Lancet 1994; 343(8911): 1454-9. Erratum in: Lancet 1995,345 (8951):738.

[54] Singh RB, Dubnov G, Niaz MA, et al. Effect of an IndoMediterranean diet on progression of coronary disease in high risk patients: a randomized single blind trial. Lancet 2002; 360: 1455-61.

[55] Gal D, Pella D, Singh RB. The effect of an alpha-linolenic acid rich diet on circadian rhythm of cardiac events. World Heart J 2008; 1 : 49-56.

[56] Sofi F, Abbate R, Gensini GF, Casini A. Accruing evidence about benefits of adherence to Mediterranean diet on health: an updated systematic review with meta-analysis. Am J Clin Nutr 2010; 92(5): 1189-96.

[57] Singh RB, Rastogi SS, Verma R, Bolaki L, Singh R, Ghosh S. An Indian experiment with nutritional modulation in acute myocardial infarction. Am J Cardiol 1992; 69: 879-85.

[58] Singh RB, Rastogi SS, Verma R, et al. Randomized, controlled trial of cardioprotective diet in patients with acute myocardial infarction: results of one year follow up. BMJ 1992; 304: 1015-9.
[59] Singh RB, Fedacko J, Vargova V, Niaz MA, Rastogi SS, Ghosh S. Effect of low W-6/W-3 ratio fatty acid Paleolithic-style diet in patients with acute coronary syndromes. A randomized, single blind, controlled trial. World Heart J 2012 (in press).

[60] Burr ML, Fehily AM, Gilbert JF. Effects of changes in fat, fish and fibre intakes on death and myocardial infarction: Diet and Reinfarction Trial (DART). Lancet 1989; 2: 757-61.

[61] Zhang L, Hou D, Chen X, et al. Exogenous plant MIR168a specifically targets mammalian LDLRAP1: evidence of crosskingdom regulation by microRNA. Cell Res 2012; 22: 107-26.

[62] Esposito $\mathrm{K}$, Marfella $\mathrm{R}$, Ciotola $\mathrm{M}$, et al. Effect of a Mediterranean-style diet on endothelial dysfunction and markers of vascular inflammation in the metabolic syndrome: a randomized trial. JAMA 2004; 292: 1440-6.

[63] Hiroyasu I, Minatsu K, Junko I, et al. Intake of fish and n3 fatty acids and risk of coronary heart disease among Japanese: The Japan public health center-based (JPHC) study cohort I. Circulation 2006; 113: 195-202.

[64] Yokoyama M, Origasa H, Matsuzaki M, et al. Effects of eicosapentaenoic acid on major coronary events in hypercholesterolaemic patients (JELIS): a randomised open-label, blinded endpoint analysis. Lancet 2007; 369: 1090-8.

[65] Takahashi T, Toda E, Singh RB, et al. Essential and NonEssential Amino Acids in Relation to Glutamate. Open Nutr J 2011; 4: 205-12.

[66] Singh RB, De Meester F, Wilczynska A, Wilson DW, Hungin APS. The liver-pancreas and brain connection in the pathogenesis of obesity and diabetes mellitus. World Heart J 2010; 2: 319-26.

[67] Wang PY, Caspi L, Lam CK, et al. Upper intestinal lipids trigger a gut-brain-liver axis to regulate glucose production. Nature 2008; 452: 1012-6.

[68] Chiu CC, Frangou S, Chang CJ, et al. Association between w-3 PUFA concentrations and cognitive functions after recovery late life depression. Am J Clin Nutr 2012; 95: 420-7.

[69] Gladman SJ, Huang W, Lim SN, et al. Improved outcome after peripheral nerve injury in mice with increased levels of endogenous omega-3 polyunsaturated fatty acids. J Neurosci 2012; 32: 563-71.

[70] Sundaram B, Holley DC, Cornelissen G, et al. Circadian and circaseptan (about weekly) aspects of immigrant Indians blood pressures and heart rate in California, USA. Biomed Pharmacother 2005; 59: S76-85.

[71] Halberg F, Cornélissen G, Otsuka K, et al. Extended consensus on need and means to detect vascular variability disorders (vvds) and vascular variability syndromes (vvss). Intl J Geronto-Geriatrics 2008; 11: 119-46.

[72] Wilson DW, Hungin APS, Howse JH, et al. Role of hormones and neuropeptides in IBS and other gastrointestinal disorders: understanding variability and chrononutrition. Open Nutr J 2011; 4: 213-25.

[73] Rhee SY, Hwang YC, Chung HY, Woo JT. Vitamin D and diabetes in Koreans: analyses based on the Fourth Korea Vitamin National Health and Nutrition Examination Survey (KNHANES), 20082009. Diabet Med 2012. [Epub ahead of print]

[74] Hideki M. Clinical study on relation of electrolytes and coronary artery disease. Proceedings of the Sixth Asian Congress of Nutrition, 16-19 September, 1991, Kuala Lumpur, Malaysia.

[75] Simopoulos AP. Is Insulin resistance influenced by dietary linoleic acid and trans fatty acidS? Free Radical Bio Med 1994; 17: 367-72.

[76] De Meester F. Wild-type land based foods in health promotion and disease prevention: the LDL-CC:HDL-CC model. In: DeMeester F, Watson RR, Eds. Foods in Health Promotion and Disease Prevention. NJ: Humana Press 2008; pp. 3-20.

[77] Kelishadi R, Mirghaffari N, Poursafa P, Gidding SS. Lifestyle and environmental factors associated with inflammation, oxidative stress and insulin resistance in children. Atherosclerosis 2009; 203 311-9.

[78] Eaton SB, Eaton SB III, Sinclair AJ, Cordain I, Mann NJ Dietary intake of long chain polyunsaturated fatty acids during the Paleolithic period. In: Simopoulos AP edition. The return of w-3 fatty acids in the food supply. Land based Animal Food 
Products and their Health Effects. World Rev Nutr Diet 1998; 83: 12-23.

[79] Singh RB, Gupta A, Pella D, Kumar A. Circadian Cardiology. World Heart J 2008; 1: 101-26.

[82] Wang L, Kong L, Wu F, Bai Y, Burton R. Preventing chronic diseases in China. Lancet 2005; 366: 1821-24.
[81] Pednekar MS, Gupta R, Gupta PC. Association of blood pressure and cardiovascular mortality in India: Mumbai Cohort Study. Am J Hypertens 2009; 22: 1076-84.

[82] Paoletti R. Nutrition and noncommunicable diseases. Available at: www.healtheurope.org [Accessed December 17, 2011].

(C) Tokunaga et al.; Licensee Bentham Open.

This is an open access article licensed under the terms of the Creative Commons Attribution Non-Commercial License (http://creativecommons. org/licenses/ by-nc/3. 0/) which permits unrestricted, non-commercial use, distribution and reproduction in any medium, provided the work is properly cited. 